\title{
Effects of Fetal Exposure to Urban Particulate Matter on the Immune System of Male Mouse Offspring
}

\author{
Seiichi Yoshida, ${ }^{*, a}$ Hirohisa Takano, ${ }^{b}$ Masataka Nishikawa,${ }^{c}$ He Miao, ${ }^{a}$ and Takamichi Ichinose ${ }^{a}$ \\ ${ }^{a}$ Department of Health Sciences, Oita University of Nursing and Health Sciences; Oita 870-1201, Japan: ${ }^{b}$ Graduate \\ School of Engineering, Kyoto University; Kyoto 615-8530, Japan: and ${ }^{c}$ National Institute for Environmental Studies; \\ Ibaraki 305-2314, Japan.
}

Received November 29, 2011; accepted May 9, 2012; published online May 22, 2012

Urban particulate matter (UPM) has been shown to have an aggravating effect on Th2-associated immune systems in adult mice. However, the effects of fetal exposure to UPM on immune response in offspring have not been elucidated. In the present study, we administered UPM (200 $\mu \mathrm{g} / \mathrm{animal})$ by intratracheal injection to pregnant dams on days 7 and 14 of gestation. Subsequently, 9- and 24-week-old male offspring were intratracheally injected with ovalbumin (OVA) (four times at 2 -week intervals) to create a mouse model of bronchial asthma. We then evaluated the progression of allergic manifestations in the offspring through histological findings, the number of inflammatory cells in bronchoalveolar lavage fluid (BALF), and protein concentration of cytokines and chemokines in BALF 5, 10, 15, and 30 weeks after birth. Histological examination showed that fetal exposure to UPM alone caused slight eosinophil and lymphocyte infiltration in the submucosa of the airway and bronchial epithelium and significant increases in the number of macrophages. Moreover, postnatal intratracheal administration of OVA to offspring exposed to UPM in utero caused significant increases in the numbers of macrophages, eosinophils, and lymphocytes and in the concentrations of their relevant cytokines and chemokines, showing that fetal exposure to UPM aggravated the chemically sensitized immune system of male offspring.

Key words immune system; next generation; particulate matter; environmental factor; cytokine; lymphocyte

Ambient air pollution has been extensively shown to affect human health. ${ }^{1-3)}$ Numerous epidemiological studies have demonstrated that exposure to urban particulate matter (UPM) air pollution, which occurs in many urban and industrial environments, is associated with an increase in childhood health risks, such as respiratory symptoms and hospital admissions for asthma. ${ }^{4-6)}$ Several recent studies have documented the adverse effects of UPM on respiratory disease in children, ${ }^{7)}$ mortality rates from reduced cardiopulmonary function, lung cancer incidence, ${ }^{3)}$ the number of low birth weight infants, ${ }^{8)}$ and asthma. ${ }^{9}$ In addition, the causes of childhood allergies, the incidence of which has increased in recent years, are related to dietary and residential environmental factors. Lifestyle environmental factors (such as environmental tobacco smoke and residential location) that affect pregnant women are also believed to be involved, although their mechanisms of action remain unknown. ${ }^{10)}$ In this regard, the effects of fetal exposure during pregnancy of women smokers include increases in the risk of intrauterine growth retardation and incidence of childhood bronchial asthma. ${ }^{11)}$ Exposure of pregnant female mice to diesel exhaust particles (DEP) can cause increased allergic susceptibility in offspring, ${ }^{12)}$ and exposure of adult mice to dioxin, which is found in trace amounts in DEP, can decrease antibody production. ${ }^{13)}$ However, the effects of ambient particulate matter inhaled by pregnant women on the health of their offspring remains to be elucidated; therefore, such an investigation is important.

Therefore, in this study, we designed experiments to simulate immune responses in offspring of pregnant women exposed to UPM. We combined exposure of pregnant ICR mice to UPM with postnatal administration of ovalbumin (OVA) to their male offspring to determine whether in utero exposure

The authors declare no conflict of interest. to UPM aggravates the postnatally sensitized immune system. We proposed the following hypotheses. In utero exposure to UPM: (1) aggravates the sensitized immune system; (2) influences lung histopathology following OVA sensitization; and (3) promotes cytokine and chemokine production in OVAexposed mice.

To test these hypotheses, we created a mouse model of bronchial asthma by exposing male offspring to OVA and then sequentially evaluated the effects of fetal exposure to UPM on their allergic manifestations.

\section{MATERIALS AND METHODS}

Animals Forty pregnant ICR mice purchased from CLEA Japan (Tokyo) were used [induction at day 5 post-coitum (p.c.; the day the plug was found was considered to be day 0 p.c.)]. Mice were divided into two groups of 20: the UPM and control groups. Up to day 16 of induction, the mice were housed five per cage, and each mouse was caged separately from day 17 of induction. The mice were kept under the following conditions: temperature, $23-25^{\circ} \mathrm{C}$; humidity, 50-70\%; and $12-\mathrm{h}$ light/dark cycle. The mice had free access to food (CE-2 solid food; CLEA, Japan) and water. The study was conducted in accordance with the Laboratory Animal Facility Usage Guidelines compiled by the Oita University of Nursing and Health Science (approval number, 310, 2009).

Preparation of Particles Preparation of particles and the characteristics of the chemical composition of the Beijing dust sample used in the present study have been reported previously. ${ }^{14)}$ The sample was collected in Beijing in 2005 using a high-volume air sampler with a quartz fiber filter (2500QT-UP; Pallflex). Almost all particles in the materials were $\leq 10 \mu \mathrm{m}$ in aerodynamic diameter. Particle size distribution was determined by analyzing a microscopic image using image analysis 
F0: Pregnant Mice

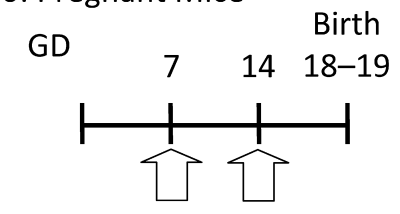

\section{F1: Offspring}
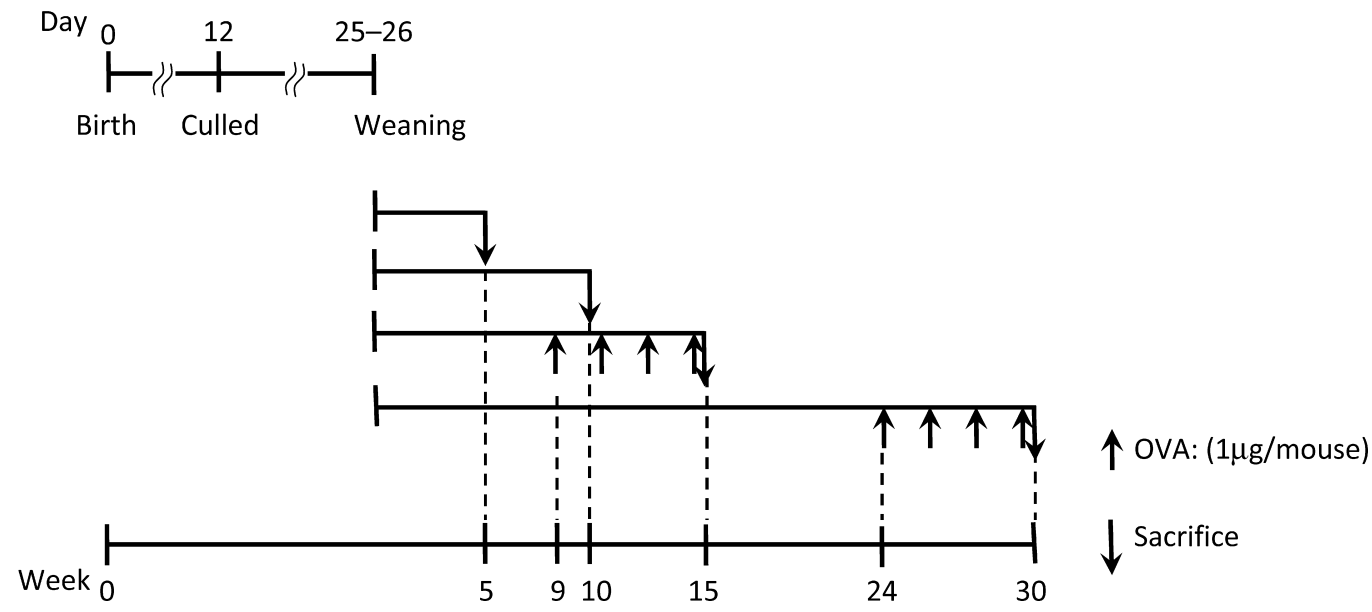

Fig. 1. Experimental Time Frame for Prenatal and Postnatal Treatments and Euthanasia

Times are expressed relative to the birth of offspring. GD, gestation day.

software (OLS3500/SFT-3500; Olympus and Shimadzu, Japan). The lower detection limit of this method was $1 \mu \mathrm{m}$. The diameters of $99 \%$ particles were $<10 \mu \mathrm{m}$, and the volume size distribution derived from the particle size measurements showed that the mode diameter was $7 \mu \mathrm{m} .{ }^{14)}$ The concentrations of chemical elements were measured by inductively coupled plasma atomic emission spectroscopy (ICP-AES, 61E Trace and ICP-750; Thermo, Jarrell-Ash, U.S.A.). The mineral composition of UPM was analyzed using an X-ray diffractometer (RINT 2000; Rigaku Corporation, Japan), and peaks were identified for quartz, feldspar, clay minerals, and gypsum. ${ }^{14)}$ UPM used in this study contained several elements such as Si (14.9\%), S (3.91\%), P (0.145\%), Cl (0.87\%), Ca (6.69\%), Al $(5.04 \%), \mathrm{Fe}(2.92 \%), \mathrm{K}(1.37 \%), \mathrm{Mn}(686 \mathrm{mg} / \mathrm{kg}), \mathrm{Ba}(874 \mathrm{mg} /$ $\mathrm{kg}), \mathrm{Sr}(469 \mathrm{mg} / \mathrm{kg}), \mathrm{Cu}(104 \mathrm{mg} / \mathrm{kg})$, and $\mathrm{As}(90 \mathrm{mg} / \mathrm{kg})$ and it also contained microbial materials such as lipopolysaccharide (LPS) and $\beta$-glucan. ${ }^{14)}$ Carbon in the material was determined using an elemental analyzer (Flush EA 1112; Thermo). UPM was heated at $360^{\circ} \mathrm{C}$ for $30 \mathrm{~min}$ in an electric heater to eliminate toxic materials (microbiological materials, sulfate, nitrate, etc.).

Particle Administration UPM was suspended in normal saline $(0.9 \% \mathrm{NaCl})$ for instillation (Otsuka Co., Kyoto, Japan). This suspension was sonicated for $5 \mathrm{~min}$ using an ultrasonic disrupter (UD-201 type with micro tip; Tomy, Tokyo, Japan) under cooling conditions. The instillation dose of particles was $200 \mu \mathrm{g} /$ mouse; the dose was determined in a previous report. ${ }^{15)}$ The particles were intratracheally administered to pregnant mice on days 7 and 14 of gestation. Exposure began after implantation and initial organ development had taken place. The interleukin (IL)-7 receptor (IL-7R) plays an essential role in the formation of $\mathrm{T}$ cells. The IL-7R cells in the $\mathrm{Lin}^{-} \mathrm{c}-\mathrm{kit}^{+}$ population (T-cell lineage-restricted progenitors/natural killer cells/dendritic cells) circulate exclusively between days 11 and 14 of gestation. ${ }^{16)}$ The amount of UPM deposited in the lungs of a single mouse every 2 weeks $(90.72 \mu \mathrm{g})$ was calculated using the value set by the Chinese national air quality limitation for inhaled UPM $\left(150 \mu \mathrm{g} / \mathrm{m}^{3}\right)$, the tidal volume, and the breathing rate. On the premise that $100 \%$ of $150 \mu \mathrm{g} / \mathrm{m}^{3}$ is accumulated in a lung $(90.72 \mu \mathrm{g})$, the instillation dose $(200 \mu \mathrm{g} /$ mouse) of particles used in the present study was 4.4 times that amount.

Offspring Mice that were delivered after an average gestation of $18 \pm 0.5 \mathrm{~d}$ were used. At the age of $12 \mathrm{~d}$, six males (from each dam) were selected, weaned at 25-26d after birth, and housed eight per cage.

Study Protocol Male ICR mouse offspring were divided into 12 groups (16 per group) according to the treatment used: normal saline (control: 5, 10, 15, and 30 weeks; OVA: 15 and 30 weeks) and fetal exposure to UPM (UPM: 5, 10, 15, and 30 weeks; UPM+OVA: 15 and 30 weeks). OVA was dissolved in the same saline as the particles, and the instillation dose was set at $1 \mu \mathrm{g}$ /mouse according to a previous report. ${ }^{17)}$ Four intratracheal instillations of OVA at 2-week intervals are needed to induce allergic lung inflammation. ${ }^{18)}$ Therefore, this method was chosen to investigate the aggravating effect of fetal exposure to UPM on allergen-related lung eosinophilia. One day after the last intratracheal administration, mice from all groups were killed by exsanguination under deep anesthesia

Table 1. Effects of UPM Exposure on Dams and Fertility

\begin{tabular}{lcc}
\hline \hline & Control & UPM \\
\hline Fertility & $100 \%$ & $90 \%$ \\
Gestation length $(\mathrm{d})$ & $18.6 \pm 0.4$ & $18.8 \pm 0.3$ \\
Litter size & $13.1 \pm 4.4$ & $13.7 \pm 3.6$ \\
Male : female ratio & $0.57 \pm 0.15$ & $0.53 \pm 0.10$ \\
\hline
\end{tabular}

Results are mean \pm S.D. 

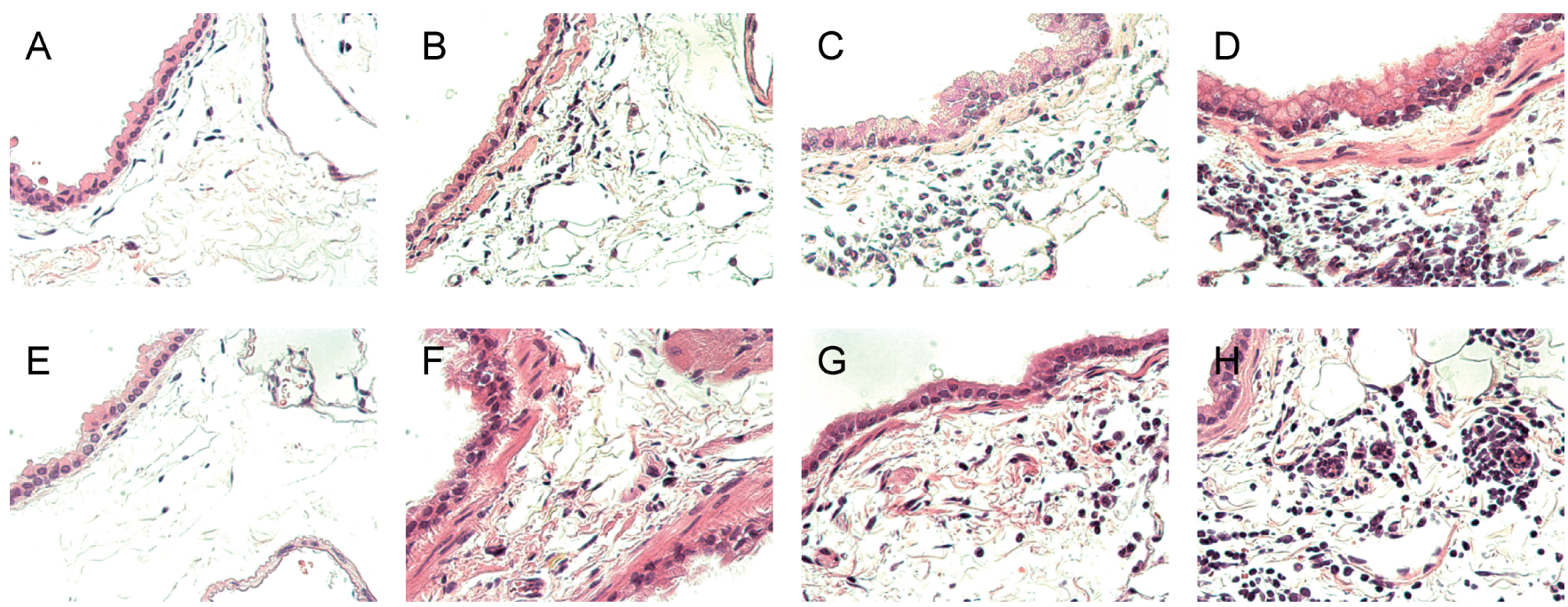

Fig. 2. Pathological Changes in the Lungs after of Fetal Exposure to Urban Particulate Matter (UPM)

A-D: 15-week-old offspring. E-H: 30-week-old offspring. A and E: controls; no pathological changes. B and F: UPM; moderate infiltration of inflammatory cells. C and G: ovalbumin (OVA); slight infiltration of inflammatory cells. D and H: UPM+OVA; marked infiltration of inflammatory cells into connective tissue around the airway. Hematoxylin and eosin (HE) staining. Original magnification $\times 100$.
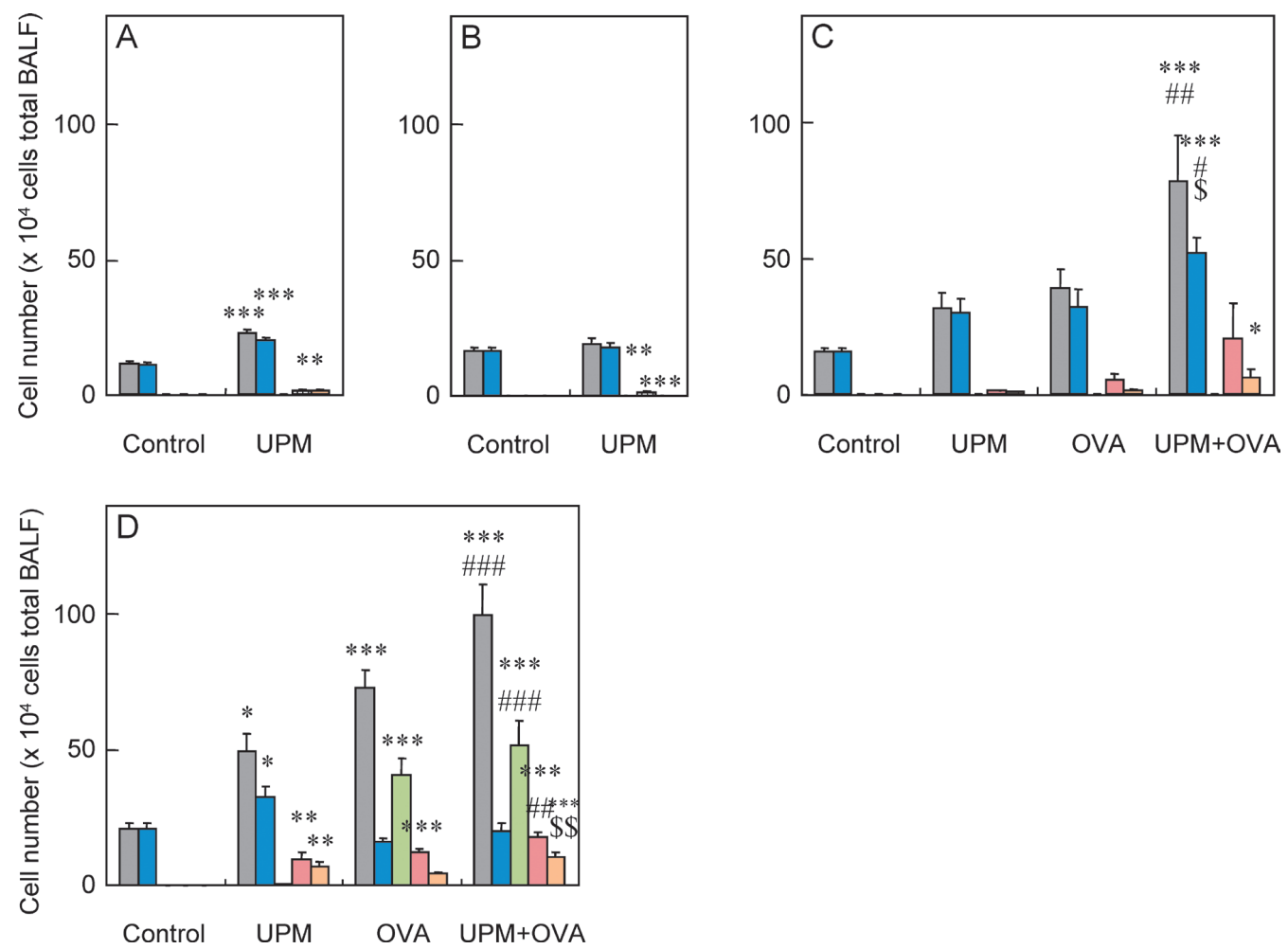

Fig. 3. Cellular Profiles in Bronchoalveolar Lavage Fluid (BALF)

A: 5-week-old offspring. B: 10-week-old offspring. C: 15-week-old offspring. D: 30-week-old offspring. All values were expressed as mean \pm standard error (S.E.) ${ }^{*} p<0.05$ vs. control; $* * p<0.01$ vs. control; $* * * p<0.001$ vs. control; ${ }^{\#} p<0.05$ vs. urban particulate matter (UPM); ${ }^{\# \#} p<0.01$ vs. UPM; ${ }^{\# \#} p<0.001$ vs. UPM; ${ }^{\$} p<0.05$ vs. ovalbumin (OVA); ${ }^{\$ \$} p<0.01$ vs. OVA. $\square$ : total cells; $\square$ : macrophages; $\square$ : neutrophils; $\square$ : eosinophils; $\square$ : lymphocytes.

with an intraperitoneal injection of pentobarbital at 5, 10, 15, and 30 weeks of age (Fig. 1).

Pathological Evaluation Eight mice from each group were used for pathological examination. The lungs were fixed in $10 \%$ neutral phosphate-buffered formalin. After separation of the lobes, 2-mm blocks were taken for paraffin embedding. Embedded blocks were sectioned at a thickness of $3 \mu \mathrm{m}$ and then stained with hematoxylin and eosin (HE). Pathological analysis of the inflammatory cells and epithelial cells in the airway of each lung lobe was performed on the slides using a Nikon Eclipse light microscope (Nikon Co., Tokyo, Japan).

Bronchoalveolar Lavage The remaining eight mice from each group were used to examine the free cell contents from bronchoalveolar lavage fluid (BALF). BALF and cell counts were performed using a method reported previously. ${ }^{17,19)}$ In brief, the tracheas were cannulated after blood collection. The 
lungs were lavaged with two injections of $0.8 \mathrm{~mL}$ sterile saline at $37^{\circ} \mathrm{C}$. The lavaged fluid was harvested by gentle aspiration. The average volume retrieved was $90 \%$ of the amount instilled $(1.6 \mathrm{~mL})$. The fluids from the two lavages were combined, cooled to $4^{\circ} \mathrm{C}$, and centrifuged at $1500 \mathrm{rpm}$ for $10 \mathrm{~min}$. The total amount of lavages collected from individual mice was measured to calculate cytokine and chemokine levels in BALF. The total cell counts of a fresh fluid specimen were determined using a hemocytometer. Differential cell counts were assessed on cytological preparations. Slides were prepared using Cytospin (Sakura Co., Ltd., Tokyo, Japan) and stained with Diff-Quik (International Reagents Co., Kobe, Japan) to identify eosinophils with red granules. A total of 300 cells were counted under oil immersion microscopy. The BALF supernatants were stored at $-80^{\circ} \mathrm{C}$ until analysis for cytokines and chemokines.

Quantitation of Cytokines and Chemokines in BALF Cytokine levels in BALF were determined using enzymelinked immunosorbent assays (ELISA). IL-5, IL-12, and tumor necrosis factor (TNF) were measured using an ELISA kit from Endogen, Inc. (Cambridge, MA, U.S.A.). Keratinocyte chemoattractant (KC), monocyte chemotactic protein (MCP)-1, macrophage inflammatory protein (MIP)- $1 \alpha$, regulated on activation, normal $\mathrm{T}$ cell expressed and secreted (RANTES), IL-13, IL-4, and eotaxin were measured using an ELISA kit from R\&D Systems Inc. (Minneapolis, MN, U.S.A.). MCP-3 was measured using an ELISA kit from Bender MedSystems Inc. (Burlingame, CA, U.S.A.).

Statistical Analysis Using KyPlot version 5 (Kyens Lab Inc.), the Tukey test for pairwise comparisons was used for statistical analysis. A $p$ value of $<0.05$ was considered to represent statistical significance.

\section{RESULTS}

Effects of UPM Administration on Maternal and Fetal Growth The effects of UPM administration on dams were determined by comparing length of gestation, litter size, fertility, and gender ratio between the control and UPM groups, and no significant differences were observed in these parameters between the two groups (Table 1).

Pathological Changes in Lungs Figure 2 illustrates the effects of fetal exposure to UPM on pathological changes in the lungs at 15 and 30 weeks of age. Fetal exposure to UPM caused a slight eosinophil and lymphocyte infiltration in the submucosa of the airway and in the bronchial epithelium (Figs. 2B,F), which was not observed in the control group (Figs. 2A, E). In the mouse model of bronchial asthma created by exposure to OVA, eosinophil and lymphocyte infiltration in the bronchial submucosa was also observed (Figs. 2C, G). In the UPM+OVA group, marked eosinophil, neutrophil, and lymphocyte infiltration was observed (Figs. 2D, H).

Effects on the Number of Inflammatory Cells in BALF To evaluate the effects of fetal exposure to UPM on BALF, we analyzed each type of inflammatory cell individually. The total number of cells in BALF was 2.0 and 2.4 times higher, respectively, in the UPM group at 5 and 30 weeks of age than in the control group ( $p<0.001$ and $p<0.05$, respectively) (Figs. $3 \mathrm{~A}, \mathrm{D})$. This number was 2.0 times higher in the UPM+OVA group at 15 weeks than in the OVA group $(p<0.05)$ (Fig. $3 \mathrm{C})$. The number of macrophages in BALF was 1.8 and 1.6 times higher in the UPM group at 5 and 30 weeks, respectively ( $p<0.001$ and $p<0.05$, respectively) (Figs. 3A,D) than in the control group. This number was 1.6 times higher in the UPM+OVA group at 15 weeks than in the OVA group $(p<0.05)$ (Fig. 3C). Fetal exposure to UPM induced neutrophils in BALF at 10 weeks and eosinophils in BALF at 5, 10, and 30 weeks (Figs. 3A, B, D). At 30 weeks of age, the number of lymphocytes in BALF was significantly higher in the UPM group compared with the control group and in the UPM+OVA group compared with the OVA group $(p<0.01)$ (Fig. 3D).

Effects on Cytokine and Chemokine Levels in BALF At age 15 weeks, fetal exposure to UPM induced no significant changes in cytokine and chemokine levels in BALF (Tables 2 and 3).

At 30 weeks, UPM+OVA significantly increased the levels of IL-5 $(p<0.05)$, IL-13 $(p<0.05)$, MCP-1 $(p<0.05)$, and RANTES $(p<0.05)$ compared with OVA alone, and significantly increased the levels of IL-5 $(p<0.05)$, IL-12 $(p<0.001)$, IL-13 $(p<0.01), \quad \mathrm{KC} \quad(p<0.001), \quad \mathrm{MCP}-1 \quad(p<0.05)$, and RANTES $(p<0.001)$ compared with UPM alone.

\section{DISCUSSION}

Recently, the prevalence of childhood allergies has been increasing, the causes of which are believed to include changes in dietary habits and residential environments. ${ }^{20)}$ Lifestyle environmental factors such as exposure of pregnant women to particulate matter are also thought to be a cause, but the mechanisms of action have not been elucidated. Therefore, in this study, we administered UPM collected from the atmosphere to pregnant mice and evaluated various effects on the immune system of their offspring. We previously reported that exposure of adult mice to microparticles, including urban particulate matter and carbon black particles, caused neutrophil infiltration in lung tissue as well as marked increase in the number of eosinophils in BALF related to administration of OVA. ${ }^{17,21)}$

In the present study, we compared lung histology in groups of mice exposed in utero to UPM (UPM group, UPM+OVA group) with that in the respective control groups (untreated group, OVA group) and found marked infiltration of inflammatory cells such as eosinophils in the submucosa of the airway in the UPM+OVA group. This suggests that inflammation is caused by fetal exposure to UPM in the absence of direct inhalation and that this process continues after birth. Although OVA-induced inflammatory cell counts in BALF were increased by fetal exposure to UPM, the increase was smaller in younger groups of mice (5-10 weeks) than in adult mice (30 weeks). Moreover, the number of macrophages was increased by fetal exposure to UPM (at 5, 15, and 30 weeks in the UPM and UPM+OVA groups), indicating enhancement of antigen presentation that might lead to later Th2-associated immune responses.

This increase in macrophages in mouse offspring exposed to UPM in utero may be related to blood cell differentiation during the fetal period, because maternal exposure could prime the fetal immune system, and subsequent immunization during the postnatal period may increase neonatal immunity. ${ }^{22)}$ Furthermore, UPM+OVA increased the number of eosinophils in BALF, which suggests the possible aggravation 
Table 2. Concentration of Cytokines in Bronchoalveolar Lavage Fluid

\begin{tabular}{|c|c|c|c|c|c|}
\hline & \multicolumn{5}{|c|}{ Cytokine expression (pg protein/total BAL supernatant) } \\
\hline & IL-4 & IL-5 & IL-12 & IL-13 & TNF \\
\hline \multicolumn{6}{|l|}{15 weeks } \\
\hline Control & 0 & 0 & $70.0 \pm 27.4$ & 0 & 0 \\
\hline UPM & 0 & 0 & $44.4 \pm 21.9$ & 0 & 0 \\
\hline OVA & 0 & $29.6 \pm 20.1$ & $121.6 \pm 54.2$ & $22.4 \pm 16.7$ & 0 \\
\hline $\mathrm{UPM}+\mathrm{OVA}$ & 0 & $52.8 \pm 36.0$ & $187.0 \pm 116.7$ & $14.7 \pm 14.7$ & 0 \\
\hline \multicolumn{6}{|l|}{30 weeks } \\
\hline Control & $14.3 \pm 6.9$ & 0 & 0 & 0 & $17.3 \pm 7.2$ \\
\hline UPM & $6.3 \pm 4.2$ & 0 & $30.3 \pm 21.3$ & 0 & $50.3 \pm 10.5$ \\
\hline OVA & $9.6 \pm 6.9$ & $10.6 \pm 3.5$ & $188.4 \pm 29.4 * *, \#$ & $7.1 \pm 1.8$ & $11.2 \pm 11.2$ \\
\hline $\mathrm{UPM}+\mathrm{OVA}$ & $9.5 \pm 4.9$ & $131.4 \pm 58.6^{*, \#, \$}$ & $277.2 \pm 64.7^{* * * \ldots \# \#}$ & $24.7 \pm 8.9^{* *, \#, \$}$ & $19.9 \pm 10.6$ \\
\hline
\end{tabular}

Table 3. Concentration of Chemokine in Bronchoalveolar Lavage Fluid

\begin{tabular}{|c|c|c|c|c|c|c|}
\hline & \multicolumn{6}{|c|}{ Chemokine expression (pg protein/total BAL supernatant) } \\
\hline & Eotaxin & $\mathrm{KC}$ & MCP-1 & MCP-3 & MIP- $1 \alpha$ & RANTES \\
\hline \multicolumn{7}{|l|}{15 weeks } \\
\hline Control & 0 & 0 & $2.4 \pm 0.1$ & 0 & 0 & $1.4 \pm 0.5$ \\
\hline UPM & 0 & 0 & $2.4 \pm 0.2$ & 0 & 0 & $1.8 \pm 0.8$ \\
\hline OVA & $2.8 \pm 2.8$ & $31.1 \pm 23.5$ & $9.8 \pm 2.9$ & $32.2 \pm 32.2$ & 0 & $2.5 \pm 1.1$ \\
\hline $\mathrm{UPM}+\mathrm{OVA}$ & $4.7 \pm 4.7$ & $52.0 \pm 27.2$ & $14.7 \pm 7.0$ & $5.4 \pm 5.4$ & $1.4 \pm 1.4$ & $3.0 \pm 1.5$ \\
\hline \multicolumn{7}{|l|}{30 weeks } \\
\hline Control & 0 & $3.9 \pm 3.9$ & 0 & 0 & 0 & 0 \\
\hline UPM & 0 & 0 & 0 & 0 & 0 & 0 \\
\hline OVA & 0 & $91.2 \pm 16.8$ & $4.6 \pm 4.6$ & 0 & $10.4 \pm 5.5$ & $74.7 \pm 24.6$ \\
\hline $\mathrm{UPM}+\mathrm{OVA}$ & $20.2 \pm 15.7$ & $116.3 \pm 20.5^{* * *}$ & $117.7 \pm 52.5^{*, \#, \$}$ & $118.4 \pm 75.7$ & $9.5 \pm 5.3$ & $329.6 \pm 102.9 * * *, \# \#, \mathrm{~S}$ \\
\hline
\end{tabular}

Bronchoalveolar lavage (BAL) was performed $24 \mathrm{~h}$ after the last intratracheal instillation of OVA. All values were expressed as mean \pm S.E. $(n=8) . * p<0.05 v s$. Control, $* * * p<0.001$ vs. Control. \#p<0.05 vs. UPM, ${ }^{\# \#} p<0.001$ vs. UPM. ${ }^{\$} p<0.05$ vs. OVA.

of type I allergic asthma by fetal exposure to UPM. This result is also consistent with lung histological analysis. From these finding, we speculate that with regard to the prevalence of childhood allergies and aggravation of asthma, the living environment of pregnant women, including smoking and exposure to pollutants such as UPM, could affect the immune system of their offspring.

The various biological components in BALF may reflect an event in the lungs. Fetal exposure to UPM increased the number of macrophages, eosinophils, and lymphocytes as well as the levels of their relevant cytokines and chemokines, such as IL-5, ${ }^{23)}$ IL-13, ${ }^{24)} \mathrm{MCP}-1,{ }^{25)}$ and RANTES, ${ }^{26)}$ induced by administration of OVA. Because RANTES is known to be strongly involved in macrophage enhancement as well as eosinophil migration and eosinophil activation, the increase in the number of macrophages and eosinophils in our study may be partly related to the higher levels of RANTES. However, there was no correlation between the number of several cell types or the concentration of cytokines and chemokines in the OVA group at 15 and 30 weeks, and other factors may contribute to the increase in cell number. Our results suggest that fetal exposure to UPM and postnatal intratracheal administration of OVA enhance allergic lung inflammation by activating the Th2-associated immune response through increase in cytokines and chemokines (such as IL-5, IL-13, MCP-1, and RANTES), which play an important role in bronchial asthma. $^{27,28)}$

Smoking in pregnant mothers, by virtue of indirect fetal exposure, can cause and increase the risk of intrauterine growth retardation, increase the incidence of asthma in children after birth $^{11,29,30)}$ and affect pulmonary function in adulthood ("fetal origin hypothesis"). ${ }^{31)}$ Thus, predispositions to health problems and disease may be formed very early in life. As shown in this study, the maternal environment and exposure to UPM in utero may affect the immune system of offspring. The particles of approximately $240 \mathrm{~nm}$ diameter did not penetrate the blood-placenta barrier. ${ }^{32)}$ Therefore, we used UPM with a mode diameter of $7 \mu \mathrm{m}^{14)}$ to study the indirect effects of fetal exposure to UPM on male offspring.

In this study, we found that fetal exposure to UPM: 1) caused an increase in the number of macrophages in BALF of offspring (UPM group); 2) caused an increase in the number of eosinophils, which regulate the immune system, induced by OVA (UPM+OVA group); and 3) induced the expression of IL-5, IL-13, MCP-1, and RANTES, which aggravate allergic inflammation (UPM+OVA group). Our findings suggest that the inhalation of UPM by pregnant women has various effects on the fetus and may be involved in the increased prevalence of childhood allergies.

Acknowledgments We appreciate the vital contribution of students at the Oita University of Nursing and Health Sciences 
to this research. This work was supported in part by a Grantin-Aid for Young Scientists (B) (11022461) from the Ministry of Education, Culture, Sports, Science and Technology of Japan and the Environmental Research and Technology Development Fund (C-1155) of the Ministry of the Environment, Japan.

\section{REFERENCES}

1) Brunekreef B, Holgate ST. Air pollution and health. Lancet, 360, 1233-1242 (2002).

2) Künzli N, Kaiser R, Medina S, Studnicka M, Chanel O, Filliger $P$, Herry M, Horak F Jr, Puybonnieux-Texier V, Quénel P, Schneider J, Seethaler R, Vergnaud JC, Sommer H. Public-health impact of outdoor and traffic-related air pollution: a European assessment. Lancet, 356, 795-801 (2000).

3) Pope CA 3rd, Burnett RT, Thun MJ, Calle EE, Krewski D, Ito $\mathrm{K}$, Thurston GD. Lung Cancer, Cardiopulmonary Mortality, and Long-Term Exposure to Fine Particulate Air Pollution. JAMA, 287, 1132-1141 (2002).

4) Dockery DW, Pope CA 3rd. Acute respiratory effects of particulate air pollution. Annu. Rev. Public Health, 15, 107-132 (1994).

5) Heinrich J, Hoelscher B, Wjst M, Ritz B, Cyrys J, Wichmann H. Respiratory diseases and allergies in two polluted areas in East Germany. Environ. Health Perspect., 107, 53-62 (1999).

6) Schwartz J, Dockery DW, Neas LM, Wypij D, Ware JH, Spengler JD, Koutrakis P, Speizer FE, Ferris BG Jr. Acute effects of summer air pollution on respiratory symptom reporting in children. Am. J. Respir. Crit. Care Med., 150, 1234-1242 (1994).

7) Fedulov AV, Leme A, Yang Z, Dahl M, Lim R, Mariani TJ, Kobzik L. Pulmonary exposure to particles during pregnancy causes increased neonatal asthma susceptibility. Am. J. Respir. Cell Mol. Biol., 38, 57-67 (2008).

8) Narasimhan TR, Craig A, Arellano L, Harper N, Howie L, Menache M, Birnbaum L, Safe S. Relative sensitivities of 2,3,7,8-tetrachlorodibenzo- $p$-dioxin-induced Cyp1a-1 and Cyp1a-2 gene expression and immunotoxicity in female B6C3F1 mice. Fundam. Appl. Toxicol., 23, 598-607 (1994).

9) Schwartz J, Neas LM. Fine particles are more strongly associated than coarse particles with acute respiratory health effects in schoolchildren. Epidemiology, 11, 6-10 (2000).

10) Bell ML, Ebisu K, Belanger K. Ambient air pollution and low birth weight in Connecticut and Massachusetts. Environ. Health Perspect., 115, 1118-1124 (2007).

11) Perera F, Tang WY, Herbstman J, Tang D, Levin L, Miller R, Ho SM. Relation of DNA Methylation of $5^{\prime}-\mathrm{CpG}$ Island of ACSL3 to Transplacental Exposure to Airborne Polycyclic Aromatic Hydrocarbons and Childhood Asthma. PLoS ONE, 4, e4488 (2009).

12) Alati R, Al Mamun A, O'Callaghan M, Najman JM, Williams GM. In utero and postnatal maternal smoking and asthma in adolescence. Epidemiology, 17, 138-144 (2006).

13) Senturia YD, McNiff Mortimer K, Baker D, Gergen P, Mitchell H, Joseph C, Wedner HJ. Successful techniques for retention of study participants in an inner-city population. Control. Clin. Trials, 19, 544-554 (1998).

14) Mori I, Nishikawa M. Characteristic of the NIES CRM No. 28 urban aerosols. Abstract of the 25th symposium on aerosol science \& technology in conjunction with international aerosol symposium. pp. 319-320 (2008).

15) Yoshida S, Hiyoshi K, Ichinose T, Takano H, Oshio S, Sugawara I, Takeda K, Shibamoto T. Effect of nanoparticles on the male reproductive system of mice. Int. J. Androl., 32, 337-342 (2009).

16) Ikawa $\mathrm{T}$, Masuda $\mathrm{K}, \mathrm{Lu} \mathrm{M}$, Minato $\mathrm{N}$, Katsura $\mathrm{Y}$, Kawamoto $\mathrm{H}$. Identification of the earliest prethymic $\mathrm{T}$-cell progenitors in murine fetal blood. Blood, 103, 530-537 (2004).
17) Hiyoshi K, Ichinose T, Sadakane K, Takano H, Nishikawa M, Mori I, Yanagisawa R, Yoshida S, Kumagai Y, Tomura S, Shibamoto T. Asian sand dust enhances ovalbumin-induced eosinophil recruitment in the alveoli and airway of mice. Environ. Res., 99, 361-368 (2005).

18) Ichinose T, Yoshida S, Hiyoshi K, Sadakane K, Takano H, Nishikawa M, Mori I, Yanagisawa R, Kawazato H, Yasuda A, Shibamoto T. The Effects of Microbial Materials Adhered to Asian Sand Dust on Allergic Lung Inflammation. Arch. Environ. Contam. Toxicol., 55, 348-357 (2008).

19) Inoue $K$, Takano $H$, Yanagisawa $R$, Ichinose $T$, Sakurai M, Yoshikawa T. Effects of nano particles on cytokine expression in murine lung in the absence or presence of allergen. Arch. Toxicol., 80, 614-619 (2006).

20) Barber K, Mussin E, Taylor DK. Fetal Exposure to Involuntary Maternal Smoking and Childhood Respiratory Disease. Ann. Allergy Asthma Immunol., 76, 427-430 (1996).

21) He M, Ichinose T, Yoshida S, Nishikawa M, Mori I, Yanagisawa R, Takano H, Inoue K, Sun G, Shibamoto T. Urban particulate matter in Beijing, China, enhances allergen-induced murine lung eosinophilia. Inhal. Toxicol., 22, 709-718 (2010).

22) Rahman MJ, Dégano IR, Singh M, Fernández C. Influence of maternal gestational treatment with mycobacterial antigens on postnatal immunity in an experimental murine model. PLOS ONE, 5, e9699 (2010).

23) Palframan RT, Collins PD, Severs NJ, Rothery S, Williams TJ, Rankin SM. Mechanisms of acute eosinophil mobilization from the bone marrow stimulated by interleukin 5: the role of specific adhesion molecules and phosphatidylinositol 3-kinase. J. Exp. Med., 188, 1621-1632 (1998).

24) D’Andrea A, Ma $X$, Aste-Amezaga $M$, Paganin $C$, Trinchieri G. Stimulatory and inhibitory effects of interleukin (IL)-4 and IL-13 on the production of cytokines by human peripheral blood mononuclear cells: priming for IL-12 and tumor necrosis factor alpha production. J. Exp. Med., 181, 537-546 (1995).

25) Haelens A, Wuyts A, Proost P, Struyf S, Opdenakker G, van Damme J. Leukocyte migration and activation by murine chemokines. Immunobiology, 195, 499-521 (1996).

26) Pan ZZ, Parkyn L, Ray A, Ray P. Inducible lung-specific expression of RANTES: preferential recruitment of neutrophils. Am. J. Physiol. Lung Cell. Mol. Physiol., 279, L658-L666 (2000).

27) Tillie-Leblond I, Hammad H, Desurmont S, Pugin J, Wallaert B, Tonnel AB, Gosset P. CC chemokines and interleukin-5 in bronchial lavage fluid from patients with status asthmaticus. Potential implication in eosinophil recruitment. Am. J. Respir. Crit. Care Med., 162, 586-592 (2000).

28) Lummus ZL, Alam R, Bernstein JA, Bernstein DI. Diisocyanate antigen-enhanced production of monocyte chemoattractant protein-1, IL-8, and tumor necrosis factor-alpha by peripheral mononuclear cells of workers with occupational asthma. J. Allergy Clin. Immunol., 102, 265-274 (1998).

29) Edwards CA, Osman LM, Godden DJ, Campbell DM, Douglas JG. Relationship between birth weight and adult lung function: controlling for maternal factors. Thorax, 58, 1061-1065 (2003).

30) Lacasaña M, Esplugues A, Ballester F. Exposure to ambient air pollution and prenatal and early childhood health effects. Eur. J. Epidemiol., 20, 183-199 (2005).

31) Kleinman MT, Sioutas C, Froines JR, Fanning E, Hamade A, Mendez L, Meacher D, Oldham M. Inhalation of concentrated ambient particulate matter near a heavily trafficked road stimulates antigeninduced airway responses in mice. Inhal. Toxicol., 19 (Suppl. 1), 117-126 (2007).

32) Wick P, Malek A, Manser P, Meili D, Maeder-Althaus X, Diener L, Diener PA, Zisch A, Krug HF, von Mandach U. Barrier capacity of human placenta for nanosized materials. Environ. Health Perspect., 118, 432-436 (2010). 